\title{
Reform and Practice of Teaching Mode of Network Engineering and Information Security Talents Training Based on $\mathrm{O} 2 \mathrm{O}$
}

\author{
Jun Tao ${ }^{1, \mathrm{a}}$, YunSheng Yan ${ }^{1, \mathrm{~b}}$, YunLing Zhang ${ }^{1, \mathrm{c}}$, Yue $\mathrm{Wu}^{1, \mathrm{~d}}$, ShenHua $\mathrm{Wu}^{1, \mathrm{e}}$, Miao Wang ${ }^{1, \mathrm{f}}$ \\ ${ }^{1}$ Computer and soft engineer department, Anhui Institute of information technology, WuHu 241000, China; \\ ataonian@126.com, ${ }^{\mathrm{b}}$ simbayen@qq.com, ${ }^{\mathrm{c}} 983146151 @$ qq.com, ${ }^{\mathrm{d}} 806465937 @ q q . c o m,{ }^{\mathrm{e}} 2455243326 @$ @q.com, \\ f1565713376@qq.com
}

\begin{abstract}
-this paper lists traditional education and its disadvantages, on the basis of traditional education, $O 20$ education model is put forward. The characteristic of $\mathbf{O 2 O}$ education mode is the combination of online and offline education. Innovative experiment plays an important role in $\mathbf{O 2 O}$ education mode. This paper introduces the concrete implementation of $\mathbf{O 2 O}$ education in Anhui Information Engineering College and some related achievements. Finally, it comes to the conclusion that $\mathbf{O 2 O}$ education model is of great significance for educational innovation and student training, while $\mathrm{O2O}$ education model is the trend of education development.
\end{abstract}

Keywords-O2O; innovation experiment; online;offline; trend

\section{INTRODUCTION}

In traditional education, teacher lecture in class, students listen to the teacher, but after class, teacher and student rarely communicate with each other, teacher can't answer student' puzzles in time, and students have less chance to do creative work. Students and teachers are all confused about the situation.

In according to the distinctive characteristics of the school and the current situation of the economic, a theoretical system of training innovative talents has been formed to meet the needs of the industry and local economic development. After extensive visiting to more than 10 institutions and more than 10 well-known enterprises, We has formed a rich and detailed research reports. From educational theories and hands-on analysis of the present status, we studied the implementation of innovative personnel training and other aspects of the implementation of a wide range of research, at last we got a relatively adequate theoretical research results. Our project team members worked in domestic and foreign academic journals published 4 research papers such as teaching, research related to the school characteristics, the guiding ideology, innovative talent training platform, academic competitions and laboratory construction etc, These theories are laid the foundation for $\mathrm{O} 2 \mathrm{O}$ practice education activities. [1]

After introducing the educational concept of $\mathrm{O} 2 \mathrm{O}$, this paper makes a further exposition on how to carry out this concept in practical education, and finally sums up the significance and Prospect of O2O Education.

\section{THEORY OF O2O SYSTEM}

$\mathrm{O} 2 \mathrm{O}$ education is a new educational model using information technology, $\mathrm{O} 2 \mathrm{Q}$ is Offline To Online. Online education requires more attention to relaxation and efficiency, offline education needs more attention to children's environmental experiences.

Through practice, Anhui Institute of information engineering has implemented $\mathrm{O} 2 \mathrm{O}$ education mode in network engineering and information security specialty, and has done a great deal of relevant theoretical research. Such research results provide a strong theoretical basis for the construction of institutional mechanisms for innovative talents training in schools. The school has gradually formed a relatively perfect system of innovative personnel training system, which has effectively guaranteed and promoted the development of innovative talents training in our university. The concrete system construction achievements include: "Anhui Information Engineering College discipline competition management regulations", "Anhui Information Engineering College Students' scientific research project funded by the project management approach", "Anhui Information Engineering College of undergraduate education of comprehensive quality assessment Interim Measures (Amendment)", "Anhui information engineering college student evaluation and implementation methods", "Anhui information engineering school full-time training of graduate students innovation ability and achievement appraisal regulations", "Anhui Information Engineering College on promoting innovation and entrepreneurship education and Entrepreneurship of university students work the implementation of opinions", "Anhui information engineering college students venture fund use and management measures" and "Anhui Information Engineering College Laboratory Management measures" etc.

According to the idea of $\mathrm{O} 2 \mathrm{O}$, talent network engineering and information security training courses is relevant to the network application personnel training curriculum ideas. Combined with the current industry demand for jobs, We formed education in $\mathrm{O} 2 \mathrm{O}$, the education is implemented by ARCS (A (Attention) + R (Relation) + C Confidence) + $\mathrm{S}$ (satisfactory) mode). The curriculum combined with the actual needs of students, the teaching process, the teaching 
online, the use of information technology education service platform, the "learn to perform a practice teaching method" (I hear you speaking, I understand you see, I ask you to answer, you do, and assist me on) evaluation process management and teaching quality evaluation[2]. Students can achieve class online testing, teaching quality data collection and analysis, monitoring and early warning functions before class preparation on line, Online teaching is in the course of "teaching method" (the four round guide action, knowledge explanation, knowledge generalization , application training, topic discussion), the four round teaching method is integrated with the teaching environment of new teaching syllabus, teaching materials, new teaching and learning. Furthermore this mode will be to achieve the "integration of teaching and comprehensive" training mode, training center and the acquisition in accordance with enterprise level instruments, the mode will graduate that students can work immediately practical operation and do the work of graduate employment skills seamless convergence.

\section{DEPENDENT DisCIPLINE COMPETITION}

According the discipline competition Oriented Innovation of credit system, we establish a foundation of open laboratory based, we create laboratory to improve with discipline construction as the basis, social cooperation is the base of discipline competition of various types of supplement, we has gradually built a "hospital, school, province, country" four level subject contest system. The leading group actively carried out related activities, studied and formulated the support mechanism for extracurricular scientific and technological cultural activities, formulated the management system for the project competition and the linkage system. It includes: organizational mechanism, incentive mechanism, base establishment, funding input, competition project and linkage mechanism, These measures ensure that discipline competition in depth and sustained development, so they have become important factors of innovative talents training. In the practical activities of this project, the project classification system construction of various disciplines competition should be strengthened. In accordance with the four dimensions of knowledge application, professional skills, ability expansion and comprehensive quality, a new discipline competition system was constructed, the classified guidance and key cultivation were carried out.

The essence of scientific research is to explore the unknown, to move into uncharted territory, and to create new products, technologies, and theories that have never existed before. To do this, we must carry forward the spirit of science, the students must be free to question, they must be allowed to participate in the contention, the school must support their spirit of adventure. The above measures stimulate the potential of students, and result in many new ideas originated in the individual. These ideas must develop in an environment of free, the creative achievements can't be derived from mechanical research planning, it can only be conceived in the complete system which is suitable for the development of student .

\section{INNOVATION AND ENTREPRENEURSHIP EDUCATION}

In order to strengthen the reform of education and teaching, we should carry out entrepreneurship education for college students, create a favorable environment and conditions for college students' innovative activities, and improve their quality of entrepreneurship. Paying attention to the practice of education, this will enhance the practical ability of students.

Construction of innovation and entrepreneurship education curriculum system include: "Open", "occupation career planning to create", "business", "organizational behavior", "public relations", "management" and the innovation and entrepreneurship education related public courses, the innovation and entrepreneurship education into professional education and cultural quality education teaching plan and credit system.

Entrepreneurship training is targeted to organize students to participate in GYB, SYB and entrepreneurship simulation training[3], through the "ladder" entrepreneurial training, training entrepreneurial awareness, learning entrepreneurship knowledge, their entrepreneurial ability will be improved.

After setting up practice platform for innovation and entrepreneurship. We encourage students to participate in the teachers' scientific research work, and accept the practice base practice in-depth campus teaching experimental teaching center, all kinds of students are invited to engage in innovative practice, We also build diversified innovative practice platform. And Strengthen the construction of university students' pioneering base. We will improve the facilities and equipment for entrepreneurial bases by strengthening the entrepreneurial base, business incubation, consultation, guidance and service functions, we also build a platform for university students' entrepreneurial practice.

It is important to establish innovative venture fund for students. The university has set up a support fund for college students' innovation and entrepreneurship projects, and has selected a number of College Students' innovative training projects, entrepreneurial training projects and entrepreneurial practice projects each year to support students in practice training for innovation and entrepreneurship.

Finally we create a strong atmosphere of innovation and entrepreneurship. We hold innovation and entrepreneurship reports and lectures, build innovative entrepreneurship classes, encourage students to carry out diversified innovation and entrepreneurship practice, and create a strong atmosphere of innovation and entrepreneurship education[4].

\section{Application Situation of O2O EdUCATION}

The research results have practical significance for guiding the training of innovative talents in Local Universities under the background of high-tech industry, and have practical experience for training innovative talents in universities.

the specific application with the following aspects, the students participate in academic competitions and college students' scientific and technological innovation activities more than ten times, the competitions include computer contest, mathematical modeling contest and Challenge Cup 
competition. Every year more than 1000 people participate in such activity. In the past three years, our college students have won 2 awards at the provincial and ministerial level in all kinds of competitions outside the school.

According to the $\mathrm{O} 2 \mathrm{O}$ philosophy of education, It is useful not only to guide students to participate in the practice of competition and strengthen the students' actual analysis and problem solving ability, but also to improve the overall quality of students; Science competition is to understand deeply and systematically the knowledge and practice process, embodies students' understanding of knowledge and skills, physical quality, psychological quality and the spirit of cooperation. Students' innovation consciousness, innovation ability and personality which has been exercised and embodied; the integration of knowledge, skills, ideas of discipline competition embodied learning discipline competition is the ability to reflect the participants using the theoretical knowledge to solve practical problems, is to test students' practical innovation ability, make students through knowledge of objective things. Observation, analysis, synthesis and evaluation, find new phenomena and rules, put forward a new theory and method, to solve the previously unresolved problems. The ability to cultivate their independent thinking and comprehensive study, careful analysis, so that students have a wide knowledge base and rigorous learning attitude; academic competition embodies the team work ability training of academic competition, competition and cooperation is complementary, innovation activities indispensable link. Through competition, stimulate the potential creative enthusiasm of students, and strive to surpass others. At the same time, innovation is also a team's cooperation and learning from each other's process. In innovation, teamwork in which everyone learn to help each other is very important; The competitions strengthen the learning behavior of the students through the inertial subject contests training consciously form good mode of thinking and behavior. In the academic competition activities, students should arrange classroom learning and competition activities, with a scientific attitude to solve the conflict of daily learning and competition, through solving such contradiction, they also gradually get the ability to solve practical problems.

\section{CONCLUSION}

This paper from the theory, system, characteristic education, academic competition, innovation and innovative education and other aspects of the $\mathrm{O} 2 \mathrm{O}$ line to line the importance of education, the goal system, organization system, education system, security system, the framework of education teaching system and evaluation system as the main body of the innovative talents in higher education. The new model provides a new way for the cultivation of innovative talents.
The school has set up college students' innovation and entrepreneurship projects support fund arrangements in accordance with the Ministry of education national innovation and entrepreneurship training program for college students, the annual selection of a group of College Students' innovative training programs, training programs for entrepreneurship and entrepreneurial practice project to give financial support, carrying out innovation and Entrepreneurship practice training students.[5] In the second batch of National Undergraduate Innovation and entrepreneurship training program, our school has 200 innovative training programs for college students, the project was approved.

China's education has been paying attention to knowledge and memory, while ignoring the development of creativity, so that most people used to imitate, and they are lack of creativity, especially in electronic equipment, machinery, transportation, medical testing, scientific instruments, communications equipment and clothing beauty. Although the imitation can also promote the economic development, but this is disadvantageous to the later development, a country must have own original technology and own scientific theory reserve, only then can we have the glorious future. Through the $\mathrm{O} 2 \mathrm{O}$ education in Anhui Information Engineering Institute, the students' imagination has been cultivated, because imagination is the premise of creativity. Einstein said a famous saying: "imagination is more important than knowledge, because knowledge is limited, but imagination is infinite, although all levels of students in China's imagination is still limited, but through the reform of traditional education, can develop their potential in the imagination, let them realize the ideal on the road further, because this is where the country of hope for the future.

\section{ACKNOWLEDGMENT}

This paper is supported by Key research project of natural science of 2017 universities of Anhui Province Education Department (Fund no: KJ2016A077, KJ2017A797) and Excellent engineer education program (Fund no: 2015zjjh079).

\section{REFERENCES}

[1] A. Green, P. L. Lumsdaine, N. Ross, P. Selinger, and B. Valiron.Quipper: A scalable quantum programming language. In Proceedings of PLDI 13, 2013.

[2] Pei T R,Zhao Z, Zeng W L et al. A cognitive improved hierarchical AODV routing protocol for cognitive wireless mesh network. Information Technology Journal, 2011, 10(2):376-384.

[3] XieXR,Computer Network[D],2013.11(6):100-104.(In Chinese).

[4] J. Miszczak. Models of quantum computation and quantum programming languages. Bull. Pol. Acad. Sci.-Tech. Sci., 59(3):305-324, 2011.

[5] Yun-Sheng Yen,"Compression of Chinese Document Images by Complex Shape Matching," The Computer Journal,Vol.56, No.11, pp.1292-1304,November, 2013 